\title{
Determination of Aflatoxins in Wheat and Wheat by- products Intended for Human Consumption, Marketed in Rio de Janeiro, Brazil
}

\author{
Felipe Machado Trombete ${ }^{1, *}$, Douglas de Ávila Moraes ${ }^{2}$, Yuri Duarte Porto ${ }^{1}$, Thaís Barbosa Santos ${ }^{1}$, \\ Glória Maria Direito ${ }^{3}$, Marcelo Elias Fraga ${ }^{3}$, Tatiana Saldanha ${ }^{2}$ \\ ${ }^{1}$ Department of Food Technology, Institute of Technology, Federal Rural University of Rio de Janeiro, Seropédica, Brazil \\ ${ }^{2}$ Department of Agronomy, Institute of Agronomy, Federal Rural University of Rio de Janeiro, Seropédica, Brazil \\ ${ }^{3}$ Department of Microbiology and Immunology Veterinary, Institute of Veterinary, Federal Rural University of Rio de Janeiro, \\ Seropédica, Brazil \\ *Corresponding author: felipetrombete@gmail.com
}

Received August 27, 2014; Revised September 11, 2014; Accepted September 19, 2014

\begin{abstract}
The consumption of wheat bran, whole-wheat grains and other whole-wheat products has grown in recent years in Brazil. These foods are considered more nutritious than the refined ones and have been associated with a reduced risk of some major chronic diseases. On the other hand, other research, carried out in Brazil, has found different groups of fungi toxins, called mycotoxins, contaminating these wheat products. Among these mycotoxins, are the aflatoxins, a group of genotoxic and carcinogenic compounds produced by Aspergillus spp. This study aimed to determine the levels of aflatoxins $B_{1}, B_{2}, G_{1}$ and $G_{2}$ in samples of whole-wheat grains and derivatives, intended for human consumption, marketed in the metropolitan region of Rio de Janeiro, Brazil. One hundred and eight samples of whole-wheat grains $(n=35)$, wheat bran $(n=32)$, whole-wheat flour $(n=26)$ and refined wheat flour $(n=15)$ marketed in hypermarkets, supermarkets and health food stores were analyzed by High Performance Liquid Chromatography with fluorescence detection (HPLC-FL). Thirty-three samples (30.6\%) were positive for at least one aflatoxin and the $B_{1}$ form had the highest prevalence in the samples. The overall average was $0.69 \mu \mathrm{g} / \mathrm{kg}$ and the contamination was the highest in the grain samples, followed by bran, whole-flour and refined flour. Just one sample showed total aflatoxins levels $\left(B_{1}+B_{2}+G_{1}+G_{2}\right)$ higher than the limit established by Brazilian legislation $(5 \mu \mathrm{g} / \mathrm{kg})$. The levels found in this study indicated that the presence of aflatoxins in wheat and wheat products consumed in Rio de Janeiro, Brazil, are not a hazard for public health.
\end{abstract}

Keywords: mycotoxins, AFB1, wheat bran, whole-wheat products, HPLC

Cite This Article: Felipe Machado Trombete, Douglas de Ávila Moraes, Yuri Duarte Porto, Thaís Barbosa Santos, Glória Maria Direito, Marcelo Elias Fraga, and Tatiana Saldanha, "Determination of Aflatoxins in Wheat and Wheat by-products Intended for Human Consumption, Marketed in Rio de Janeiro, Brazil." Journal of Food and Nutrition Research, vol. 2, no. 10 (2014): 671-674. doi: 10.12691/jfnr-2-10-3.

\section{Introduction}

Aflatoxins are a group of structurally related toxic compounds produced by the fungi species Aspergillus spp, principally $A$. flavus and A. parasiticus. These species grow on certain foods or feeds under favorable conditions of temperature and humidity [1]. The major aflatoxins of concern are designated $B_{1}, B_{2}, G_{1}$, and $G_{2}$, and are classified by the International Agency of Research on Cancer (IARC) as carcinogens agents to humans (in Group 1) [2]. They are usually found together in various foods and the $\mathrm{B}_{1}$ form has the highest carcinogenic potential among the known mycotoxins $[3,4]$. Since there is no Acceptable Daily Intake (ADI) for aflatoxins, as they are genotoxic and carcinogenic substances, exposure through food should be kept as low as possible [5]. To protect the consumers from this hazard, different countries have set different limits for the presence of aflatoxins in wheat and wheat products, ranging from $4 \mu \mathrm{g} / \mathrm{kg}$ in the European Union to $30 \mu \mathrm{g} / \mathrm{kg}$ in India [6].

Cereal grains contaminated with aflatoxins represent a public health problem due to the high toxicity of these substances and also because they remain partially stable during the industrial processes when manufacturing derived products $[7,8]$. The milling of the wheat can minimize mycotoxin concentrations in the fraction used for human consumption as these toxins are redistributed mainly in the bran, which is predominately used for animal feed $[9,10]$. However, the human consumption of wheat bran as a direct source of dietary fiber has grown in recent years, mainly because it is a cheap product and has a high dietary fiber content [11]. For this reason, the wheat bran intended for human consumption must have low mycotoxin levels in order not to compromise the safety of the final product [12]. 
The consumption of wheat bran, whole-wheat grains and other whole-wheat products has grown in recent years in Brazil. These foods are considered more nutritious than the refined ones and have been associated with a reduced risk of some major chronic diseases, including cardiovascular diseases and some cancers [12,13]. On the other hand, other research, carried out in the country, has shown that these foods may be contaminated with different groups of mycotoxins [14,15,16,17].

In Brazil, there are few studies concerning the occurrence of aflatoxins in wheat and wheat products. In other countries, such as, Tunisia, Lebanon and Turkey, high levels of aflatoxins have been reported in wheat and derivatives, which represents a health risk to consumers $[18,19,20]$.

This study aimed to determine the levels of aflatoxins $B_{1}, B_{2}, G_{1}$ and $G_{2}$ in samples of whole-wheat grains and derivatives, intended for human consumption, marketed in Rio de Janeiro, Brazil.

\section{Material and Methods}

\subsection{Sampling}

During January 2013 to February 2014, samples of whole wheat grain $(n=35)$, wheat bran $(n=32)$, whole wheat flour $(n=26)$ and refined wheat flour $(n=15)$ were acquired from different hypermarkets, supermarkets and health food stores in the metropolitan region of Rio de Janeiro, Brazil, totaling 108 samples. Packets of 0.5 to 1 $\mathrm{kg}$ were collected and then transported to the laboratory for analysis.

\subsection{Chemicals and Reagents}

Aflatoxins $B_{1}, B_{2}, G_{1}$ and $G_{2}$ standards were purchased from Sigma (St. Louis, MO, USA). HPLC-grade acetonitrile and methanol were purchased from Tedia (São Paulo, SP, Brazil). The other solvents used for extraction were of analytical grade (Vetec, Rio de Janeiro, RJ, Brazil). Deionized water used was obtained from a Milli$\mathrm{Q}^{\circledR}$ purification system (Millipore, MA, USA). Filter papers (No. 1) were purchased from Whatman (Maidstone, UK) and $0.45 \mu \mathrm{m}$ PVDF membranes (Durapore ${ }^{\circledR} 13 \mathrm{~mm}$, Millipore) were used for filtration.

\subsection{Preparation of Standard Solutions}

The standards of aflatoxins $B_{1}(5 \mathrm{mg}), B_{2}, G_{1}$ and $G_{2}(1$ $\mathrm{mg}$ ) were dissolved in methanol. Individual stock solutions $(50 \mu \mathrm{g} / \mathrm{mL})$ and working solutions $(2 \mu \mathrm{g} / \mathrm{mL})$ were prepared by appropriate dilution in methanol and their concentrations were confirmed by UV spectroscopy (Shimadzu UV-1201, Kyoto, Japan), according to the Association of Official Analytical Chemists (AOAC) [22].

\subsection{Aflatoxins Extraction and Derivatization}

Aflatoxin determinations were carried out in triplicate for each one of the 108 samples. The methodology used for extraction and purification was performed according to the Institute Adolfo Lutz [23], with minor adaptations, as follows. Water $(5 \mathrm{~mL})$ at $60^{\circ} \mathrm{C}$ was added to $15 \mathrm{~g}$ of the grounded sample in an Erlenmeyer flask. Then $50 \mathrm{ml}$ of chloroform was added to the flask and agitated in a Shaker
(Orbit Shaker 3520) for $45 \mathrm{~min}$. The chloroform extract was filtered through filter paper and $25 \mathrm{~mL}$ was collected, and then evaporated to dryness in a water bath at $65^{\circ} \mathrm{C}$ under a $\mathrm{N}_{2}$ flow. The dried extract was resuspended with $25 \mathrm{~mL}$ of methanol in an ultrasound bath (Thornton T7) for $10 \mathrm{sec}$ and transferred to a separatory funnel containing $25 \mathrm{~mL}$ of $\mathrm{NaCl}$ aqueous solution $(4 \% \mathrm{w} / \mathrm{v})$. Then $25 \mathrm{~mL}$ of hexane was added and the mixture was stirred vigorously for $30 \mathrm{sec}$, after which the hexane phase (top) was discarded. This step was repeated with another $25 \mathrm{~mL}$ of hexane. Subsequently, $25 \mathrm{~mL}$ of chloroform was added to the separatory funnel, with vigorous shaking for $30 \mathrm{sec}$. This step was repeated with another $25 \mathrm{~mL}$ of chloroform and then evaporated until dryness in a water bath at $65{ }^{\circ} \mathrm{C}$ under a $\mathrm{N}_{2}$ flow. For the aflatoxin extractions from wheat bran twice the volume of chloroform was used, and for the analysis of the flours water was not added.

Based on the derivatization procedure described by AOAC [24], the extract was resuspended in $0.6 \mathrm{~mL}$ of acetonitrile, submitted to an ultrasound bath for $30 \mathrm{sec}$ and $1.2 \mathrm{~mL}$ of the derivatizing solution (water: trifluoroacetic acid: glacial acetic acid at 7: 2: 1, v/v/v) was added. The solution was maintained in a water bath at $65^{\circ} \mathrm{C}$ for $9 \mathrm{~min}$. Finally, the extract was filtered through a $0.45 \mu \mathrm{m}$ membrane and injected into the HPLC-FL system.

\subsection{HPLC-FL Analysis}

The quantification of the aflatoxins was carried out in a High Performance Liquid Chromatography system, using a fluorescence detector (Agillent 1100 Series, Waldbronn, Germany) (excitation at $365 \mathrm{~nm}$ and emission at $450 \mathrm{~nm}$ ), a Rheodyne injector $(20 \mu \mathrm{L})$, a $_{18}$ column (Ace, $250 \mathrm{~mm}$ $\mathrm{x} 4.6 \mathrm{~mm}, 5 \mu \mathrm{m})$ and an isocratic mobile phase, consisting of water: methanol: acetonitrile $(7: 2: 1, \mathrm{v} / \mathrm{v} / \mathrm{v})$ at a flow rate of $1.0 \mathrm{~mL} \mathrm{~min}{ }^{-1}$. The results were expressed by the mean of the triplicates, in $\mu \mathrm{g} / \mathrm{kg}$.

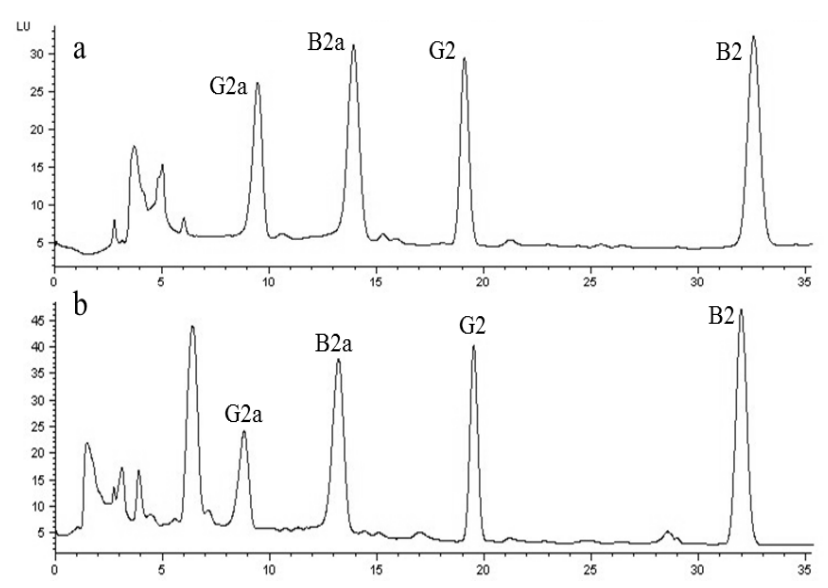

Figure 1. Chromatograms obtained by HPLC-FL in wheat grains (a) and wheat bran samples (b) spiked with approximately $5 \mu \mathrm{g} \mathrm{kg}^{-1}$ of aflatoxins $B_{1}, B_{2}, G_{1}$ and $G_{2}$. Aflatoxin $G_{2 a}$ and $B_{2 a}$ are derivatized forms of the $G_{1}$ and $\mathrm{B}_{1}$

The methodology used in this study was previously inhouse validated and proved to be suitable for aflatoxin determination in the matrices evaluated (grains, bran and flours), with good levels of recovery (70.2-108.5\%) and repeatability (lower than $15 \%$ ), with limits of detection and quantification corresponding to 0.6 and $1.2 \mu \mathrm{g} / \mathrm{kg}$, respectively [25]. The retention times were approximately 
9, 13, 20 and 32 min for aflatoxin $\mathrm{G}_{2 \mathrm{a}}$ (derivatized form of $G_{1}$ ), $B_{2 a}$ (derivatized form of $B_{1}$ ), $G_{2}$ and $B_{2}$, respectively, as presented in Figure 1.

\subsection{Statistical Analysis}

Statistical analyses were performed using Sisvar® 5.3 Build 77 (UFLA, Brazil). A probability value of 0.05 was used to determine the statistical significance in ANOVA and in the Tukey test.

\section{Results and Discussion}

One hundred and eight wheat and wheat by-products, marketed in Rio de Janeiro, Brazil, were analyzed for the presence of aflatoxins $B_{1}, B_{2}, G_{1}$ and $G_{2}$. Thirty-three samples $(30.6 \%)$ were positive for at least one aflatoxin and the $\mathrm{B}_{1}$ form had the highest prevalence in the samples. It was detected in $27.8 \%$, with the highest level found in a grain sample, corresponded to $4.2 \mu \mathrm{g} / \mathrm{kg}$. The $\mathrm{G}_{1}$ and $\mathrm{G}_{2}$ were detected in only $10.2 \%$ and $0.9 \%$ of the samples, respectively. The $\mathrm{B}_{2}$ form was not detected in any sample (Figure 1).
Refined wheat flour

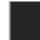

Whole wheat flour

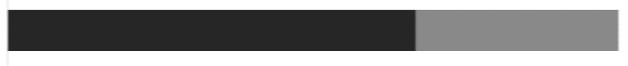

Wheat bran

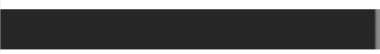

Grains

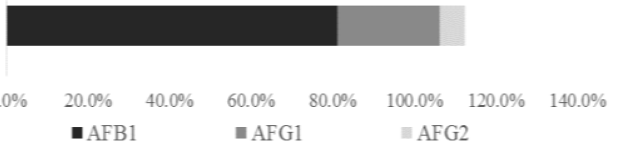

Figure 2. Occurrence of aflatoxins $B_{1}, G_{1}$ and $G_{2}$ in positive samples. The $\mathrm{B}_{2}$ form was not detected in any sample

Just one sample (wheat grain with $6.2 \mu \mathrm{g} / \mathrm{kg}$ ) showed total aflatoxins $\left(B_{1}+B_{2}+G_{1}+G_{2}\right)$ higher than the limit established by Brazilian legislation for cereals in general $(5 \mu \mathrm{g} / \mathrm{kg})$. The overall average was $0.69 \mu \mathrm{g} / \mathrm{kg}$ and the contamination was the highest in the grain samples, followed by bran, whole-flour and refined flour, as presented in Table 1. The levels of total aflatoxins in positive samples did not differ $(p>0.05)$ between the analyzed foods.

Table 1. Aflatoxin levels in samples of wheat grains, wheat bran and wheat flours, marketed in Rio de Janeiro, Brazil

\begin{tabular}{|c|c|c|c|c|c|}
\hline Food & $\boldsymbol{n}$ & Positive samples & Mean in positive samples $\mathbf{1}(\boldsymbol{\mu g} / \mathbf{k g})$ & Highest value found $(\boldsymbol{\mu g} / \mathbf{k g})$ & $\mathbf{M P L}(\boldsymbol{\mu g} / \mathbf{k g})$ \\
\hline Wheat grains & 35 & $45.7 \%$ & $2.2^{\mathrm{a}}$ & 5 \\
\hline Wheat bran & 32 & $40.6 \%$ & $2.4^{\mathrm{a}}$ & 5.2 \\
\hline Whole wheat flour & 26 & $7.7 \%$ & $2.3^{\mathrm{a}}$ & 5 \\
\hline Refined wheat flour & 15 & $6.7 \%$ & $1.2^{\mathrm{a}}$ & 5.4 \\
\hline Total & 108 & $30.6 \%$ & $2.2^{\mathrm{a}}$ & 5 \\
\hline
\end{tabular}

${ }^{1}$ Means followed by the same letter in the column are not different (P>0.05) by Tukey test. $n$ - Number of samples analyzed. MPL - Maximum

Permitted Level adopted by Brazilian regulations [12].

Considering the European Union limit for the presence of aflatoxins in wheat $(4 \mu \mathrm{g} / \mathrm{kg})$, one sample of wheat bran containing $4.79 \mu \mathrm{g} / \mathrm{kg}$ would also be considered unfit for human consumption [26]. The current legislation about mycotoxins prevailing in Brazil came into force in 2011 [12]. After this date, the present study is the first report giving data on levels of aflatoxins in wheat and wheat products intended for human consumption marketed in Brazil. However, more studies evaluating the occurrence of aflatoxins and other groups of mycotoxins in wheat and derivatives should be carried out in different regions of the Brazil, as these foods are an important source of nutrients for the Brazilian population diet.

\section{Conclusion}

From a total of 180 samples analyzed, 33 (30.5\%) were positive for at least one aflatoxin and just one sample (wheat grain) showed levels higher than the limit established by Brazilian legislation (5 $\mu \mathrm{g} / \mathrm{kg}$ ). The contamination was the highest in the grain samples, followed by bran, whole-flour and refined flour. The levels found in this study indicate that the presence of aflatoxins in wheat and wheat products consumed in Rio de Janeiro, Brazil, is not hazard for public health.

\section{Acknowledgement}

The authors are grateful for the financial support provided by CAPES - Coordenação de Aperfeiçoamento de Pessoal de Nível Superior.

\section{References}

[1] FSA. Food Standards Agency. "Mycotoxins commonly found in food and feed.", 2013. [Online]. Available at: http://www.food.gov.uk/business-

industry/farmingfood/mycotoxins/about/\#.U95bOWNHTIU. [Accessed Ago. 25, 2014].

[2] IARC, International Agency for Research on Cancer. "IARC Monographs on the evaluation of carcinogenic risks to humans Some traditional herbal medicines, some mycotoxins, naphthalene and styrene" 82. 2002. [Online]. Available at:

monographs.iarc.fr/ENG/Monographs/vol82/mono82.pdf [Accessed Ago. 25, 2014].

[3] FDA. U.S. Food and Drug Administration. "Foodborne Pathogenic Microorganisms and Natural Toxins Handbook" 2012. [Online]. Available:

http://www.fda.gov/Food/FoodborneIllnessContaminants/CausesO fIllnessBadBugBook/ucm071020.htm. [Accessed Ago. 25, 2014].

[4] EFSA. European Food Safety Authority. "Aflatoxins (sum of $B_{l}$, $\left.B_{2}, G_{l}, G_{2}\right)$ in cereals and cereal-derived food products" 2013. Available at: www.efsa.europa.eu/en/supporting/pub/406e.html [Accessed Ago. 25, 2014].

[5] EFSA. European Food Safety Authority. "Aflatoxins in food, 2013. [Online]. Available at: http://www.efsa.europa.eu. [Accessed Ago. 25, 2014].

[6] Trombete, F.M.T., Saldanha, T., Direito, G.M. and Fraga, M. E., "Aflatoxinas y tricotecenos en trigo y derivados: Incidencia de la contaminación y métodos de determinación," Rev. Chil. Nutr., 40 (2). 181-188. Jun.2013.

[7] Bullerman, L.B. and Bianchini A., "Stability of mycotoxins during food processing.," Int. J. Food Microbiol., 119 (2). 140-146. Oct.2007.

[8] Giménez, I., Herrera, M., Escobar, J., Ferruz, E., Lorán, S., Herrera, A., and Ariño, A., "Distribution of deoxynivalenol and zearalenone in milled germ during wheat milling and analysis of 
toxin levels in wheat germ and wheat germ oil," Food Control, 34 (2). 268-273. Dec.2013.

[9] Herrera, M., Juan, T., Estopaña, G., and Ariño, A "Comparisoxynivalenol, ochratoxin $\mathrm{A}$ and aflatoxin $\mathrm{B}_{1}$ levels in conventional and organic durum semolina and the effect of milling," J. Food Nutr. Res., 48 (2). 92-99. Ago.2009.

[10] Cheli, F., Pinotti, L., Rossi, L., and Dell'Orto, V. "Effect of milling procedures on mycotoxin distribution in wheat fractions: A review," LWT - Food Sci. Technol., 54 (2). 307-314. Dec.2013.

[11] Vidal, A., Marín, S., Ramos, A.J., Cano-sancho, G., and Sanchis, V., "Determination of aflatoxins, deoxynivalenol, ochratoxin A and zearalenone in wheat and oat based bran supplements sold in the Spanish market," Food Chem. Toxicol., 53 (1). 133-138. Ago.2013.

[12] BRASIL. Ministry of Health. "Resolução $R D C n^{\circ} 7$, de 18 de Fevereiro de 2011. Dispõe sobre limites máximos tolerados (LMT) para micotoxinas em alimentos" 2011. [Online]. Available at: http://bvsms.saude.gov.br/bvs/saudelegis/anvisa/2011/res0007_18 _02_2011_rep.html [Accessed Ago. 25, 2014]。

[13] Stevenson, L., Phillips, F., O’Sullivan, K., and Walton, J., "Wheat bran: its composition and benefits to health, a European perspective.," Int. J. Food Sci. Nutr., 63 (8).1001-1013. Dec.2012.

[14] Okarter, N., and Liu, R.H., "Health benefits of whole grain phytochemicals.," Crit. Rev. Food Sci. Nutr., 50 (3). 193-208. Mar.2010.

[15] Del Ponte, E.M., Garda-Buffon, J., and Badiale-Furlong, E., "Deoxynivalenol and nivalenol in commercial wheat grain related to Fusarium head blight epidemics in southern Brazil," Food Chem., 132 (2). 1087-1091. May.2012.

[16] Santos, J.S., Souza, T.M., Ono, E.Y.S., Hashimoto, E.H., Bassoi, M.C., Miranda, M.Z., Itano, E.N., Kawamura, O., Hirooka, E.Y., "Natural occurrence of deoxynivalenol in wheat from Paraná State, Brazil and estimated daily intake by wheat products.," Food Chem., 138 (1). 90-95. May.2013.

[17] Savi, G.D., Piacentini, K.C., Tibola, C.S., and Scussel, V.M., "Mycoflora and deoxynivalenol in whole wheat grains (Triticum aestivum L.) from Southern Brazil.," Food Addit. Contam. Part B, Surveill., 7 (3). 232-237. Sep.2014.

[18] Almeida-Ferreira, G.C., Barbosa-Tessmann, I.P., Sega, R., and Machinski, M. "Occurrence of zearalenone in wheat and corn based products commercialized in the State of Paraná, Brazil" Braz. J. Microbiol., 44 (2). 371-375. Jan.2013.

[19] Joubrane, K., Khoury, A.E.L., Lteif, R., Rizk, T., Kallassy, M., Hilan, C., and Maroun, R., "Occurrence of aflatoxin $\mathrm{B}_{1}$ and ochratoxin A in Lebanese cultivated wheat," Mycotoxin Res., 27 (4). 249-257. May.2011.

[20] Aydin, A., Gunsen, U., and Demirel, S., "Total Aflatoxin, Aflatoxin $\mathrm{B}_{1}$ and Ochratoxin A Levels in Turkish Wheat Flour," $J$. Food Drug Anal., 16 (2). 48-53. Fev.2008.

[21] Ghali, R., Hmaissia-khlifa, K., Ghorbel, H., Maaroufi, K., and Hedili, A., "Incidence of aflatoxins, ochratoxin A and zearalenone in Tunisian foods," Food Control, 19 (9). 921-924. Sep.2008.

[22] AOAC. Association of Official Analytical Chemists. "Official Methods of Analysis 971.22 - Standards for Aflatoxins", Chapter 49" 2000.

[23] Instituto Adolfo Lutz. Métodos físico-químicos para análise de alimentos. Chapter CCIV - Micotoxinas. 759-801. 2008. [Online]. Available at: http://www.crq4.org.br/sms/files/file/analisedealimentosial_2008. pdf. [Accessed Ago. 25, 2014].

[24] AOAC. Association of Official Analytical Chemists. "Official methods of analysis 994.08 - Derivatization of standards for aflatoxins", Chapter 49. 2005.

[25] Trombete, F.M., Santos, T.B., Direito, G.M., Fraga, M.E., Saldanha, T., "In-house validation of a method for determining aflatoxins $\mathrm{B}_{1}, \mathrm{~B}_{2}, \mathrm{G}_{1}$ and $\mathrm{G}_{2}$ in wheat and wheat by-products," Pesq. Agropec. Trop., 44 (3). 255-262. 2014.

[26] EU. European Union. "Commission Regulation (EU) No 165/2010 of 26 February 2010 amending Regulation (EC) No 1881/2006 setting maximum levels for certain contaminants in foodstuffs as regards aflatoxins.," 8-12. 2010. 